\title{
Ovarian Cancer Pathogenesis: A Model in Evolution
}

\author{
Alison M. Karst ${ }^{1}$ and Ronny Drapkin ${ }^{1,2}$ \\ ${ }^{1}$ Department of Medical Oncology, Center for Molecular Oncologic Pathology, Dana-Farber Cancer Institute, 44 Binney Street, \\ Boston, MA 02115, USA \\ ${ }^{2}$ Department of Pathology, Brigham and Women's Hospital, 75 Francis Street, Boston, MA 02115, USA
}

Correspondence should be addressed to Ronny Drapkin, ronny_drapkin@dfci.harvard.edu

Received 1 June 2009; Accepted 23 June 2009

Academic Editor: Tian-Li Wang

Copyright ( $) 2010$ A. M. Karst and R. Drapkin. This is an open access article distributed under the Creative Commons Attribution License, which permits unrestricted use, distribution, and reproduction in any medium, provided the original work is properly cited.

\begin{abstract}
Ovarian cancer is a deadly disease for which there is no effective means of early detection. Ovarian carcinomas comprise a diverse group of neoplasms, exhibiting a wide range of morphological characteristics, clinical manifestations, genetic alterations, and tumor behaviors. This high degree of heterogeneity presents a major clinical challenge in both diagnosing and treating ovarian cancer. Furthermore, the early events leading to ovarian carcinoma development are poorly understood, thus complicating efforts to develop screening modalities for this disease. Here, we provide an overview of the current models of ovarian cancer pathogenesis, highlighting recent findings implicating the fallopian tube fimbria as a possible site of origin of ovarian carcinomas. The ovarian cancer model will continue to evolve as we learn more about the genetics and etiology of this disease.
\end{abstract}

\section{Introduction}

Ovarian cancer afflicts $\sim 204000$ women worldwide each year, including $\sim 21650$ Americans $[1,2]$. Despite its relatively low incidence rate, ovarian cancer is an extremely lethal disease. Globally, it claims 125000 lives per year, making it the seventh leading cause of cancer-related deaths among women [2]. In the United States, ovarian cancer mortality is even higher; it ranks as the fifth deadliest malignancy among women, with an estimated 15520 deaths per year [1]. In fact, of the top ten cancer types afflicting American women in 2008, ovarian cancer had the highest death-toincidence ratio, exceeding even that of lung cancer [1]. Its high mortality is primarily due to difficulties in diagnosing early stage disease. Although the 5 years survival rate for stage I ovarian cancer is $>90 \%$, stage I diagnoses are more often the exception than the rule. Most patients $(\sim 75 \%)$ present with advanced stage (III/IV) tumors, for which the 5 years survival rate is a dismal $30 \%$ [1]. This is not surprising when one considers the anatomical problem-the ovaries are a pair of tiny organs, only $\sim 2-4 \mathrm{~cm}$ in diameter, suspended on either side of the uterus and not readily accessible by pelvic examination unless significantly enlarged. By definition, a stage I tumor is confined to the ovary [3] and is therefore unlikely to be noticed without the aid of a sensitive screening test. Unfortunately, there are currently no effective screening modalities for detecting ovarian cancer in asymptomatic individuals. Furthermore, there are no tell-tale physical signs of the disease. Typical symptoms - which include abdominal discomfort, bloating, gas, nausea, and urinary urgency-are vague and often mistaken for gastrointestinal problems [4, 5]. In many cases, symptoms may not even present until the tumor has reached an advanced stage. Consequently, ovarian cancer is frequently nicknamed the "silent killer" [5-7].

\section{Early Detection}

The best tools currently available for detecting early-stage ovarian cancer are transvaginal sonography (TVS) and serum biomarker testing. TVS is a noninvasive technique that provides detailed images of ovary size and shape, facilitating the detection of ovarian masses. Large-scale studies evaluating its ability to identify early-stage tumors have reported mixed results [8-13]. Overall, TVS has not demonstrated adequate sensitivity to warrant its use in screening general populations. Furthermore, even in the most optimistic reports, it is clear that TVS can only detect tumors that cause a significant increase in ovarian 
volume [13]. This is especially worrisome in the case of serous-type tumors which may spread rapidly from the ovary to other pelvic sites prior to ovarian enlargement. For instance, in a large study by van Nagell et al., four women were diagnosed with late-stage ovarian cancer within 12 months of a negative TVS scan [9]. In addition, there is debate as to whether all ovarian tumors actually arise from the ovary and not from adjacent pelvic sites such as the fallopian tube or peritoneum [14]. Serous tumors involving the ovary but originating from extraovarian sites can never be classified as "stage I" according to current staging systems, since they are never confined to the ovary. It has therefore been proposed that the definition of "early stage" ovarian carcinoma should be based on minimal tumor volume rather than anatomical location [14]. TVS screening may also be prone to false-positive results because it cannot always distinguish malignant ovarian tumors from benign adnexal masses, such as cysts and fibromas, which are highly prevalent among postmenopausal women $[15,16]$. While TVS alone is not a suitable front-line screening modality, it can serve as a useful secondary screening tool after serum biomarker testing $[17,18]$.

Serum biomarker testing is an ideal form of cancer detection because it is minimally invasive, cost effective, easily administered, nonsubjective, and is not contingent upon primary ovarian involvement. The most well-studied ovarian cancer biomarker is CA-125, a high molecular weight transmembrane glycoprotein expressed by coelomic- and Müllerian-derived epithelia, including that of the fallopian tube, endometrium, and endocervix [19]. It is not expressed by normal ovarian epithelium [20]. CA-125 is detected at low levels $(<35 \mathrm{U} / \mathrm{mL})$ in the serum of healthy individuals but is elevated in $\sim 50 \%$ of stage I ovarian cancer patients and $\sim 90 \%$ of advanced-stage patients [21-24]. CA-125 elevation is predominantly associated with serous tumors, the most common and most lethal subtype of ovarian carcinoma [25]. Serum levels directly correlate with the level of CA-125 protein production in tumor cells and appear to reflect a state of active tumor growth [25-27]. Following its discovery in 1981 [28], CA-125 was intensely studied to evaluate its potential for detecting early-stage ovarian cancer, and many encouraging results were reported. For example, a study of prediagnostic serum samples found that CA- 125 was elevated in $25 \%$ of ovarian cancer patients 5 years prior to their diagnoses [29]. However, it was later discovered that serum CA-125 levels can be increased by a range of benign conditions (such as pelvic inflammatory disease, endometriosis, uterine fibroids, and ovarian cysts) making false positivity a problem [30]. So far, CA-125 has not demonstrated adequate sensitivity to support its use in screening asymptomatic women for early-stage ovarian cancer [31], but longer-term studies are still underway. In the meantime, CA-125 remains a valuable tool for monitoring response to chemotherapy and for detecting disease relapse following treatment $[32,33]$.

In an attempt to improve sensitivity for early disease detection, two approaches have been taken. (1) Obtaining longitudinal measurements of CA-125, and (2) using multiple tumor markers. The former approach assumes that CA-
125 levels are likely to remain stable in patients with benign conditions but will increase over time if an ovarian cancer is in progress. Thus, by plotting serial CA-125 measurements over a period of years, one can calculate the "probability of ovarian cancer" for an individual patient using a Bayesian algorithm [34-36].

The latter approach aims to combine CA-125 with one or more additional tumor markers, most notably human epididymis protein 4 (HE4). HE4 is a glycoprotein secreted by Müllerian epithelia of the female reproductive tract as well as male epididymis [37]. Like CA-125, it is not expressed by normal ovarian epithelium but appears in some premalignant ovarian cysts (cortical inclusion cysts) and is strongly expressed by the most common ovarian tumor subtypes (serous and endometrioid) [37]. HE4 is both more sensitive and specific than CA-125 in detecting early-stage ovarian cancer and is not associated with benign conditions to the same degree, enabling HE4 to distinguish malignant ovarian tumors from benign cystic lesions [38-40]. When used in combination to detect early-stage disease, CA-125 and HE4 perform better than either marker alone and can be used to stratify patients into high- and low-risk groups [40, 41]. Although HE4 was recently approved by the US Food and Drug Administration for use in monitoring ovarian cancer patients following treatment, larger-scale studies are required to determine whether a dual CA-125/HE4 biomarker test is suitable for screening asymptomatic women in the general population.

In addition, some groups have assembled panels of biomarkers to create a so-called "composite marker." For example, Zhang et al. measured the serum levels of four tumor markers (CA-125II, CA72-4, CA15-3, and M-CSF) in sets of healthy women, women with benign ovarian conditions, and women with ovarian cancer [42]. From their measurements, they derived an artificial neural network (ANN) model that could distinguish healthy women from those with early-stage ovarian cancer. The sensitivity of their ANN-derived composite index was 25-28\% higher than that of CA-125 alone. Similar reports of increased sensitivity upon employment of multiple tumor markers have been reported by other groups $[43,44]$. However, serum tests for multiple biomarkers are not yet widely available.

\section{Ovarian Cancer Is a Heterogeneous Disease}

Some of the greatest challenges in detecting and treating ovarian cancer stem from its heterogeneous nature. The term "ovarian cancer" refers not to a single disease, but to a diverse group of malignancies affecting the ovary. In general, ovarian tumors may develop from one of three cell types: epithelial cells, sex cord-stromal cells (including granulosa, theca, and hilus cells), or germ cells (oocytes). Although $\sim 40 \%$ of all ovarian tumors are nonepithelial in origin, such lesions rarely progress to a malignant state and account for only $10 \%$ of ovarian cancers [45]. This paper will therefore focus exclusively on epithelial-derived ovarian tumors, which constitute the predominant and most lethal forms of the disease. Epithelial ovarian carcinomas are themselves a heterogeneous group of neoplasms that exhibit a wide range of 


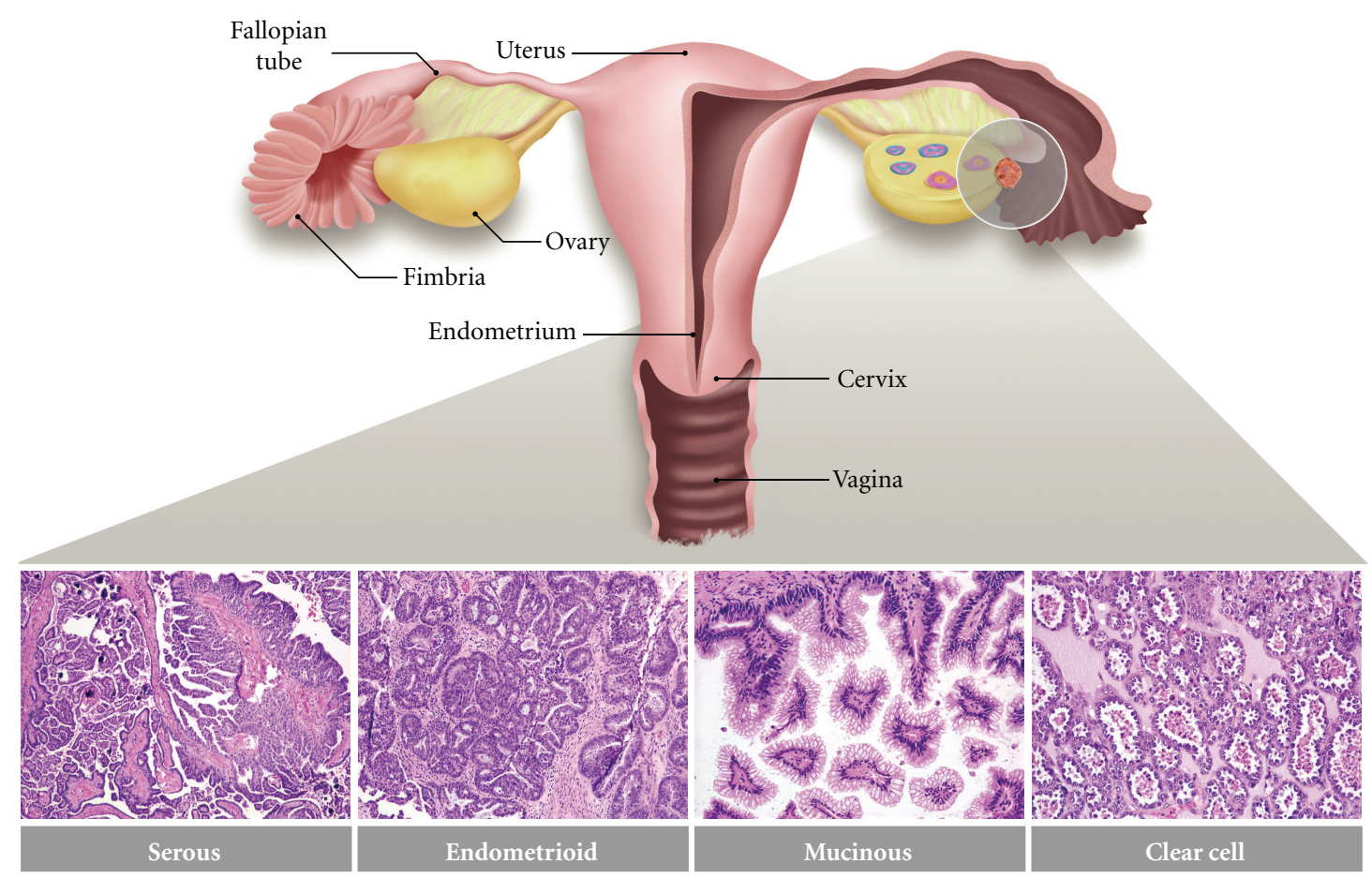

FIGURE 1: The major histologic subtypes of ovarian carcinoma. Serous carcinomas resemble fallopian tube epithelium, endometrioid carcinomas resemble endometrial glands, and mucinous carcinomas resemble endocervical epithelium. Photographs show representative tumor sections stained with hematoxylin and eosin. The shaded circle represents the general anatomical location from which ovarian carcinomas are thought to arise. The pink and blue entities within the cross-sected ovary represent maturing ovarian follicles.

tumor morphologies, clinical manifestations, and underlying genetic alterations. Upon diagnosis of malignancy, ovarian tumors are surgically staged to determine how far they have extended beyond the ovary [3]. Stage I indicates confinement to the ovary. Stage II tumors extend beyond the ovary to adjacent pelvic structures such as the fallopian tube or uterus. Stage III indicates metastasis to the peritoneum and/or regional lymph nodes. Stage IV tumors have metastasized beyond the peritoneum to distant sites. Additionally, tumors are classified by subtype. Current clinical guidelines set forth by the World Health Organization (WHO) recognize eight histologic tumor subtypes: serous, endometrioid, mucinous, clear cell, transitional cell, squamous cell, mixed epithelial, and undifferentiated [46]. The three most common-serous, endometrioid, and mucinous-are characterized by their morphological resemblance to various mucosal tissues of the female reproductive tract, all of which exhibit Müllerian differentiation (Figure 1). More specifically, serous tumors resemble fallopian tube epithelium, endometrioid tumors resemble endometrial glands, and mucinous tumors resemble endocervical epithelium (though clinically, distinguishing mucinous ovarian tumors from those of the gastrointestinal tract is more relevant) [47]. This phenomenon is quite remarkable when one considers that all ovarian tumor subtypes are conventionally thought to develop from ovarian surface epithelium, a monolayer of nondescript, poorly differentiated mesothelial cells [48]. Within each subtype, tumors are further described as either benign, malignant, or borderline and, depending upon tumor subtype, classified as low- or high-grade. Borderline tumors are considered to have low malignant potential and/or indolent behavior.

There are major differences in incidence, tumor behavior (low versus high malignant potential), and clinical outcome between each histologic subtype. For example, it has been estimated that $\sim 50 \%$ of malignant ovarian tumors are serous carcinomas, while $\sim 25 \%$ are endometrioid carcinomas, $\sim 10 \%$ are mucinous carcinomas, and only $\sim 5 \%$ are clear cell carcinomas [45]. However, a study by Seidman et al. reported incidences of $70 \%, 7 \%, 10 \%$, and $<3 \%$ for serous, endometrioid, clear cell, and mucinous carcinomas, respectively, in a series of 220 consecutive cases of invasive ovarian cancer, suggesting that traditional distribution figures may vary considerably [49]. In terms of behavior, serous carcinomas tend to be aggressive, high-grade neoplasms that spread rapidly throughout the pelvis, while endometrioid and mucinous carcinomas are typically low-grade lesions, confined to the ovary $[50,51]$. Clear cell and endometrioid carcinomas, unlike other subtypes, are strongly linked to endometriosis [52-56], leading some to believe that endometriosis may be a precursor to these lesions $[57,58]$. Tumor histology can also strongly impact clinical response. For instance, late-stage serous and clear cell carcinomas, both of which have similar 5 years survival rates (20-30\%), differ markedly in their response to chemotherapy; serous tumors are (initially) highly responsive, while clear cell tumors are notoriously resistant $[59,60]$. 
Genetic and biomarker profiling studies of ovarian cancer have revealed that each tumor subtype is associated with a unique "molecular signature." For example, gene expression profiling can readily distinguish mucinous and clear cell ovarian tumors from other subtypes, regardless of tumor stage or grade [61,62]. Similarly, microRNA (miRNA) profiling of ovarian carcinomas has identified certain miRNAs that exhibit histotype specificity [63]. Gene expression profiling has also demonstrated that ovarian clear cell tumors are distinctly different from other forms of ovarian cancer and have more in common with clear cell tumors of other organs, such as renal clear cell carcinomas [64]. Even within one histotype, differences in tumor behavior may be underscored by distinct expression profiles. For example, Bonome et al. found that serous borderline tumors (SBTs), which account for $10-15 \%$ of serous ovarian neoplasms and are associated with vastly improved survival, cluster separately from high-grade serous carcinomas in hierarchical clustering analyses [65]. Moreover, SBTs are genetically more similar to normal ovarian surface epithelium than to advanced serous tumors. A recent immunohistochemical biomarker study of 500 ovarian carcinomas found that 20 of 21 candidate tumor biomarkers had significantly different expression patterns in each tumor subtype and that two thirds of the biomarkers lost their prognostic value when survival analyses were made subtype specific [66]. These results clearly indicate that each ovarian tumor subtype constitutes a distinct disease and should be treated as such in the contexts of detection, treatment, and prognosis.

Perhaps the most important characteristic of any tumor is the combination of genetic alterations that underlie its development and drive its progression. In this arena, ovarian tumors again exhibit heterogeneity. Mucinous, endometrioid, and low-grade serous tumors typically acquire mutations in a variety of genes such as KRAS, BRAF, PTEN, $\beta$-catenin, and TFG- $\beta R I I$ [51], all of which belong to signaling pathways controlling cell growth and proliferation, among other processes. Conversely, high-grade serous tumors appear to arise following a mutation in TP53 [67] or, in the case of familial ovarian carcinoma, BRCA1, $B R C A 2, M L H 1$, or MSH2 [68, 69]. All five genes are tumor suppressors that function in DNA damage signaling and repair $[69,70]$, suggesting that DNA damage is an especially important factor in the etiology of serous ovarian carcinoma. Mutations in TP53 can even prompt an immunological response, leading to $p 53$ autoantibody production in some patients with high-grade ovarian carcinomas [71].

Despite the high degree of phenotypic and genotypic variability that exists between different forms of ovarian carcinoma, virtually all patients are treated identically upon diagnosis: cytoreductive surgery, followed by platinum-based chemotherapy. Although many tumors are initially responsive to this treatment, most develop platinum resistance and $\sim 70 \%$ recur at some point [72]. Ultimately, only $30 \%$ of advanced-stage patients survive five years beyond their diagnoses [1]. Over the past several decades, great advances have been made in the surgical techniques and chemotherapy regimens used to treat ovarian cancer. Yet, despite the best efforts of surgeons, oncologists, and researchers, the 5 years survival rate has improved by only $8 \%$ since 1975 [1]. It has thus become apparent that a "blanket approach" to ovarian cancer treatment does not suffice. We must now shift our focus towards the development of targeted therapies capable of exploiting the molecular and genetic characteristics of individual tumor subtypes. This task is made difficult by the fact that we are still very much in the dark when it comes to understanding ovarian cancer etiology. Unlike other malignancies such as cervical or colon cancer, whose pathogeneses are well characterized, the sequence of events leading to ovarian carcinoma development remains a subject of ongoing debate.

\section{Evolution of the Ovarian Cancer Model}

4.1. Ovarian Surface Epithelium and Cortical Inclusion Cysts. The traditional view of ovarian cancer asserts that all tumor subtypes share a common origin in ovarian surface epithelium (OSE). OSE is a flat-to-cuboidal layer of uncommitted mesothelial cells covering the exterior surface of the ovary. During ovulation, follicular rupture and oocyte release inflict physical trauma upon the ovarian surface, creating a breach in the OSE that must be repaired. Over the course of a woman's reproductive life, this process of damage and repair is repeated multiple times. Accordingly, OSE cells exhibit a high degree of plasticity that facilitates tissue remodeling; they express both epithelial and mesenchymal markers and can transition from an epithelial to mesenchymal phenotype [73-76]. In addition to physical trauma, OSE cells are subjected to ovulation-associated inflammatory cytokines and reactive oxygen species that are capable of damaging DNA [77]. Accrual of DNA damage by OSE cells may increase their susceptibility to transformation. Furthermore, as women age, the ovarian surface develops numerous invaginations into the cortical stroma. These invaginations frequently pinch off and become entrapped within the stroma, forming circular OSE-lined structures termed "cortical inclusion cysts" (CICs) [78]. Once inside the ovary, the epithelial cells lining CICs are exposed to a new hormonerich milieu that is thought to induce a differentiation or "metaplasia" into more complex epithelium resembling that of Müllerian-derived organs [78, 79]. Alternatively, it is postulated that in women experiencing endometriosis or endosalpingiosis (i.e., abnormal shedding of endometrial or tubal mucosa, respectively, into the pelvis), remnants of Müllerian-derived epithelia may adhere to the ovarian surface and become incorporated into a CIC $[78,80]$. Several hormones acting upon the ovary (e.g., gonadotropins, estrogens, and androgens) have growth-promoting properties that may induce proliferation of epithelial cells within CICs [81]. If the epithelial cells also happen to harbor unresolved DNA damage, they may be prime targets for neoplastic transformation, eventually giving rise to ovarian carcinomas. The OSE-CIC model can account for several important features of ovarian tumorigenesis, including (1) acquisition of Müllerian characteristics by OSE-derived tumors, (2) the cystic nature of benign ovarian tumors and the retention of cystic features by their malignant 
counterparts, and (3) the presence of low-grade and borderline tumors within the cortical stroma of the ovary. This model is also consistent with well-established epidemiologic data indicating that a decrease in ovulatory cycles (most commonly due to parity or oral contraceptive use) is the greatest risk-reducing factor for ovarian cancer in female populations [82]. However, this model has its limitations. For example, it does not explain why invasive endometrioid and mucinous carcinomas are frequently associated with borderline tumors in the ovary, whereas invasive serous carcinomas are not. Nor does this model address the clear differences in genetic alterations that exist between tumor subtypes. If all ovarian tumors develop from CICs within the ovary, then why do they have such different outcomes and such divergent genotypes? Perhaps the most curious phenomenon, not accounted for by this model, is the existence of extraovarian peritoneal carcinomas. Such tumors are histologically identical to serous ovarian carcinomas but do not involve the ovary and thus, are considered to arise de novo in the peritoneum.

4.2. Two-Pathway Model. The two-pathway model was proposed by Shih and Kurman in 2004 in an attempt to integrate most of the clinical, histopathological, and molecular genetic findings concerning ovarian cancer. In particular, they sought to account for the differences in TP53 and KRAS mutational frequencies observed between serous borderline tumors (SBTs) and serous carcinomas [83-85]. SBTs comprise a subset of serous ovarian tumors (including those referred to as atypical proliferative serous tumors and micropapillary serous carcinomas) that are noninvasive, appear to develop from benign serous cystadenomas, and progress very slowly towards low-grade serous carcinoma $[86,87]$. The indolent behavior of SBTs contrasts sharply with that of conventional high-grade serous tumors, which spread rapidly and metastasize early in their course. Furthermore, SBTs do not harbor the TP53 mutations that are characteristic of high-grade serous carcinomas. These observations prompted the formulation of a new model that classifies all ovarian tumors as either Type I or Type II [51].

Type I tumors include all major histotypes (serous, endometrioid, mucinous, clear cell, and transitional) but exhibit low-grade nuclear and architectural features, slow growth, and can be linked to well-defined benign ovarian precursor lesions. The most common genetic alterations seen among Type I tumors are KRAS and BRAF mutations, both of which activate the oncogenic MAPK signaling pathway [88]. Mutually exclusive KRAS and BRAF mutations are observed in $\sim 65 \%$ of SBTs but are rarely seen in highgrade serous carcinomas [58, 89]. KRAS mutations also occur in $\sim 60 \%$ of mucinous, $5-16 \%$ of clear cell, and $4-5 \%$ of endometrioid Type I carcinomas [51]. PTEN mutations, which typically result in constitutive PI3K signaling, occur in $\sim 20 \%$ of Type I endometrioid neoplasms [90]. The MAPK and PI $3 K$ pathways are related; they eventually converge upon a common downstream translation factor, eIF4B [91], which may represent an important signaling axis in Type I tumor development. WNT and TGF- $\beta$ signaling pathways are also of potential importance for Type
I tumor pathogenesis, based on the presence of $\beta$-catenin mutations in $16-54 \%$ of endometrioid tumors and TGF$\beta$ RII mutations in $66 \%$ of Type I clear cell tumors [51]. Interestingly, all of the genes altered in Type I ovarian tumors are components of pathways that become intimately related during the process of epithelial-to-mesenchymal transition $[92,93]$.

Type II ovarian tumors, on the other hand, are infrequently associated with benign or borderline ovarian precursor lesions. They are comprised almost exclusively of highgrade serous carcinomas but also include two less common subtypes-mixed epithelial and undifferentiated carcinomas. Type II ovarian tumors are overwhelmingly TP53 mutated (50-80\%) and may also exhibit gene amplification and overexpression of HER2/neu (10-20\%) and AKT2 (12$18 \%)$ oncogenes [94-99]. Shih and Kurman's two-pathway hypothesis reconciles most of the phenotypic and genotypic observations pertaining to ovarian tumors and it certainly improves upon the conventional OSE-CIC model. However, their model leaves one critical question unanswered-how do Type II tumors arise and does their pathogenesis include a well-defined precursor lesion?

4.3. Fallopian Tube as a Site of Origin. This question may have been answered by a series of studies investigating the prevalence of occult fallopian tube cancer in women with germline $B R C A$ gene mutations. Inherited mutations in BRCA1 or BRCA2 are associated with familial ovarian and breast cancer syndromes and account for $\sim 11-15 \%$ of ovarian carcinomas [100]. Mutations in either gene confer a $15-40 \%$ lifetime risk of developing ovarian cancer [101]. Many women with germline $B R C A$ mutations $(B R C A+)$ elect to undergo risk-reducing bilateral salpingo-oophorectomy (ovary and fallopian tube removal), after which their ovaries are thoroughly examined for evidence of occult cancer. Until recently, the fallopian tubes were not closely examined following such surgeries, and thus, early-stage tubal cancers were rarely detected and severely under reported in $B R C A+$ patients.

In 2001, Piek et al. drew attention to this issue when they reported that sectioning and examination of fallopian tubes from $12 B R C A+$ patients revealed a high incidence $(50 \%)$ of epithelial dysplasia [102]. The fallopian tube epithelium (FTE) is a columnar cell layer composed of two specialized cell types-secretory and ciliated cells. In their study, Piek et al. noticed that dysplastic regions of FTE exhibited a shift towards the secretory phenotype, with complete loss of ciliated cells and the acquisition of proliferative capacity (indicated by Ki67 immunoreactivity). Shortly thereafter, several other groups reported finding occult tubal cancers in the fallopian tubes of $B R C A+$ women, with incidence rates ranging from $0.9-17 \%$ [103-105].

However, not until a few years later did it become apparent that the distal end of the fallopian tube, the "fimbria", rather than the proximal region of the tube, was the most crucial site to look for early serous tumors. In 2006, Medeiros et al. conducted a study similar to that of Piek et al., examining the fallopian tubes of $13 B R C A+$ women undergoing bilateral salpingo-oophorectomy [106]. 
Medeiros et al. employed a specific protocol for Sectioning and Extensively Examining the FIMbria (SEE-FIM). Their examination uncovered a high incidence $(38 \%)$ of serous tubal intraepithelial carcinomas in the fallopian tube, but none in the ovaries. Furthermore, $80 \%$ of these carcinomas appeared exclusively in the fimbriated end of the fallopian tube, indicating that the fimbria is the preferred site of serous carcinogenesis in $B R C A+$ women. Similarly, Callahan et al. reported on a cohort of $122 B R C A+$ women in which 7 early carcinomas were found, all originating in the fimbrial/ampullary region. A third study by Kindelberger et al. documented the occurrence of tubal intraepithelial carcinomas (TICs) in 55 consecutive cases of pelvic (i.e., ovarian, tubal, and peritoneal) serous cancer, not selected for $B R C A$ status [107]. Of 42 cases designated "serous ovarian carcinoma," $71 \%$ involved the fallopian tube, and $48 \%$ of these contained a TIC. Again, TICs were located predominantly $(93 \%)$ in the fimbrial region. These results suggest that many high-grade serous "ovarian" tumors may actually be of tubal origin, arising from the distal region of the fallopian tube, but then quickly spreading to the nearby ovary.

This concept, while at first provocative, is quite plausible upon consideration. The fimbria lies in extremely close proximity to ovarian surface epithelium and is therefore exposed to the same inflammatory (and potentially carcinogenic) microenvironment. At the fimbriated end of the tube the internal tubal mucosa (endosalpinx) meets the outer tubal serosa which, in turn, is continuous and indistinguishable from the peritoneum. It is therefore easy to imagine that transformed FTE cells, early in their progression, may slough off and migrate to the ovarian surface or directly to the peritoneum, with minimal ovarian involvement. This could explain the existence of some extraovarian peritoneal carcinomas.

During their initial study of tubal mucosa [106], Medeiros et al. noted stretches of secretory-type cells exhibiting strong p53 immunoreactivity but appearing nonproliferative and histologically benign. The observed loss of ciliated cells was reminiscent of dysplastic lesions earlier described by Piek et al. [102]. They termed these regions of strong p53 immunoreactivity "p53 signatures" (Figure 2). In an attempt to further characterize these entities, Lee et al. examined the occurrence of $p 53$ signatures in the fimbria of both $B R C A+$ women and women undergoing hysterectomies for benign indications (such as fibroids, endometriosis, or prolapse) [108]. They found that p53 signatures were equally common in the nonneoplastic fimbria of both $B R C A+$ and control subjects, suggesting that they are a "normal" phenomenon. They also discovered that $p 53$ signatures stain strongly for the DNA damage marker $\gamma$-H2AX (Figure 2). Gamma-H2AX is a phosphorylated form of the histone protein H2AX. Phosphorylation of H2AX by DNA damagesensing kinases ATM and ATR occurs rapidly at sites of DNA double strand breakage [109]. The presence of so-called " $p 53$ signatures" in the fimbriae of normal women provides the first evidence that, under normal physiologic conditions, fimbrial epithelial cells experience genotoxic damage and trigger a DNA damage response. Lee et al.'s study also made several key observations about the relationship between $p 53$ signatures and TICs: 1 p53 signatures occur more frequently in fimbriae where TICs are also present, 2 p53 signatures are composed exclusively of secretory cells which, like TICs, exhibit a serous phenotype, 3 p53 signatures and TICs, when concurrent, share evidence of DNA damage and exhibit identical TP53 mutations, indicating a common origin, and 4 TICs can be distinguished from $p 53$ signatures by their increased proliferative capacity (i.e., MIB1 positivity and increased Cyclin E expression). Based on their observations, Lee et al. hypothesized that p53 signatures could represent the elusive ovarian serous carcinoma precursor. To determine whether $p 53$ signatures also occur in ovarian epithelium, Folkins et al. examined the ovaries and fallopian tubes of $75 B R C A+$ women. They detected a total of 29 signatures in tubal mucosa but only 1 in OSE and 0 in CICs [110], confirming that p53 signatures preferentially arise in FTE rather than OSE.

In light of these developments, Lee et al. formulated a model of ovarian cancer which incorporates the fimbria as a major site of origin for serous carcinomas. Their model asserts that there are two distinct pathways leading to ovarian tumorigenesis. The first route is the traditional OSE-CIC pathway, in which OSE (or in some cases FTE, endometrium, or peritoneum) is entrapped within CICs and induced to undergo Müllerian metaplasia within the ovarian stroma, giving rise to mostly endometrioid, mucinous, and serous borderline tumors via a series of step-wise mutations (reviewed in [111]). This pathway leads to the formation of Shih and Kurman's "Type I" tumors. The second pathway involves the fallopian tube fimbria, where a combination of TP53 mutation and genotoxic stress leads to the clonal expansion of secretory epithelial cells, forming a preneoplastic precursor lesion or "p53 signature." Additional genetic "hits" in the absence of functional TP53 enable these cells to acquire a proliferative capacity, facilitating progression to TIC (Figure 3). Identifying the genetic targets of such "hits" is currently a subject of intense research. Serous TICs have the ability to spread rapidly, moving from the fimbria to adjacent pelvic structures (e.g., the ovarian surface, uterine serosa, or peritoneal membranes) or exfoliating into the peritoneal cavity. This second pathway leads to the formation of Shih and Kurman's "Type II" tumors and, importantly, defines a precursor lesion for these tumors. The origin of genotoxic stress in the fimbrial microenvironment remains speculative at this point but is thought to include inflammatory cytokines and reactive oxygen species associated with ovulation. Accordingly, a recent paper has reported that $p 53$ signatures are associated with lower parity in $B R C A+$ women, suggesting that ovulation is indeed a risk factor for p53 signature development in the fimbria [112].

This new model of ovarian cancer accounts for nearly all aspects of the disease and, for the first time, describes a stepby-step pathogenesis model for the deadliest and most enigmatic of all ovarian tumors-serous carcinoma. The clinical implications of this model were recently reviewed $[111,113]$ and suggest that a thorough examination of the fallopian tube fimbria should be conducted during routine pathologic evaluations of salpingo-oophorectomy specimens. It is 


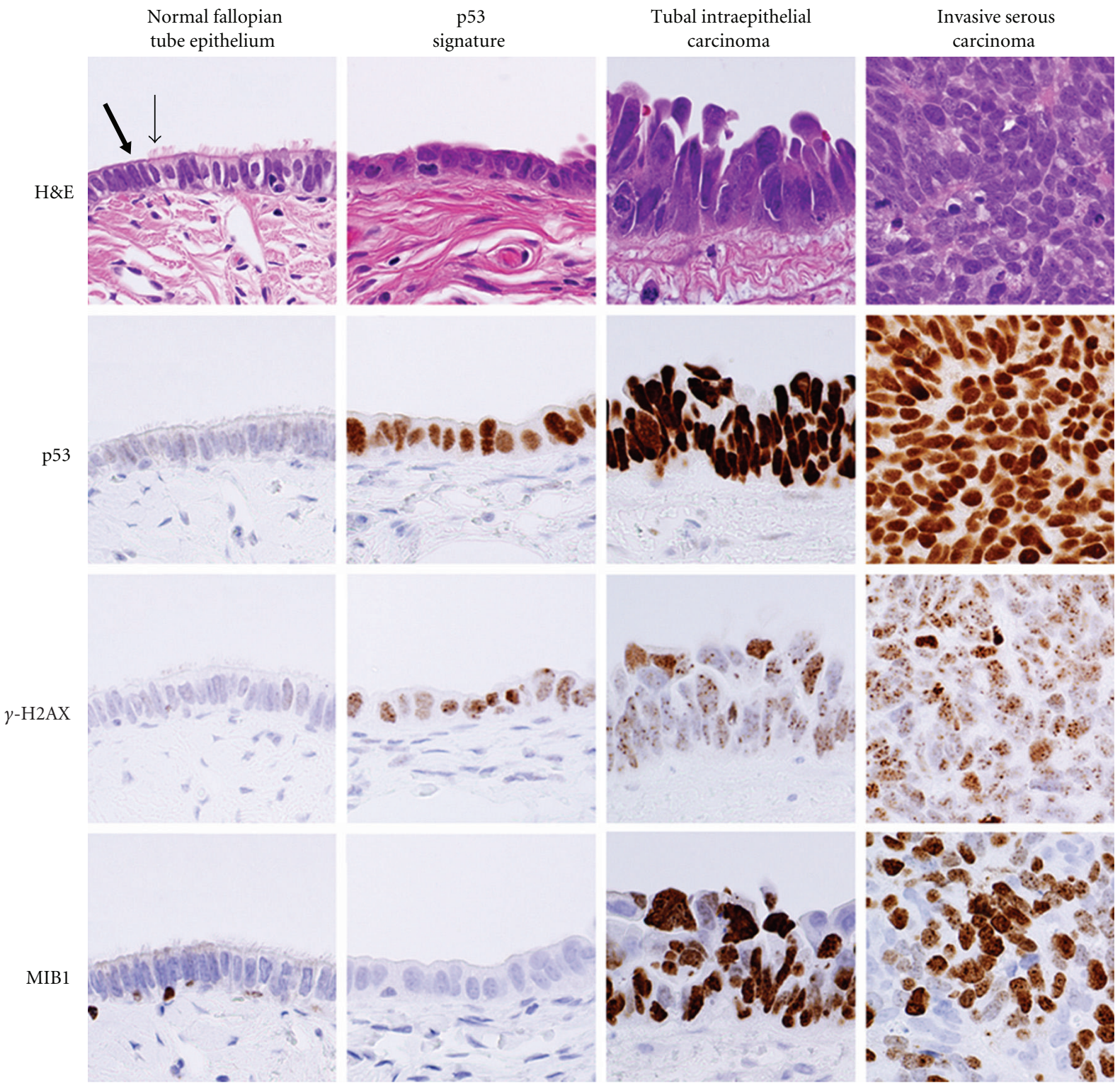

FIGURE 2: Pathologic features of the morphological continuum from normal fallopian tube epithelium to invasive serous carcinoma. Normal fallopian tube epithelium (FTE), containing both secretory (thick arrow) and ciliated (thin arrow) cells, is typically immunonegative for $p 53$, $\gamma$-H2AX (a marker of DNA damage), and MIB1 (antibody against Ki67; a proliferation marker). The benign "p53 signature" is composed of a stretch of secretory cells exhibiting strong $p 53$ expression and evidence of DNA damage (i.e., nuclear $\gamma$-H2AX foci), but showing no signs of proliferation. Upon progression to TIC, there is an acquisition of proliferative capacity, as evidenced by gain of MIB1 immunoreactivity. High levels of $p 53, \gamma$-H2AX, and MIB1 typically persist after a TIC develops into invasive serous carcinoma.

important to note, however, that this new model is based largely upon descriptive pathological evidence and has not been experimentally validated.

\section{Experimental Models of Ovarian Cancer}

In order to elucidate the molecular mechanisms driving ovarian carcinoma development, we must first be able to model the disease using suitable in vitro and in vivo systems. Several sophisticated mouse models of ovarian carcinoma currently exist. Most are based on the traditional OSECIC model of ovarian tumorigenesis and therefore seek to transform murine ovarian surface epithelium (MOSE) in vivo. For example, Connolly et al. induced MOSE transformation in vivo by introducing SV40 T-Ag (large and small) into these cells under the control of a Müllerian inhibitory substance II receptor (MISIIR) promoter element [114]. Other groups have used the Cre-Lox system to conditionally knockout tumor suppressor genes TP53 and $R b$ in murine ovaries [115]. Orsulic et al. developed a unique model in which a series of oncogenes was introduced directly into the MOSE cells of an adult mouse [116]. Their system employed an avian retroviral vector that requires retroviral receptor (TVA) expression by target cells. This is normally achieved 


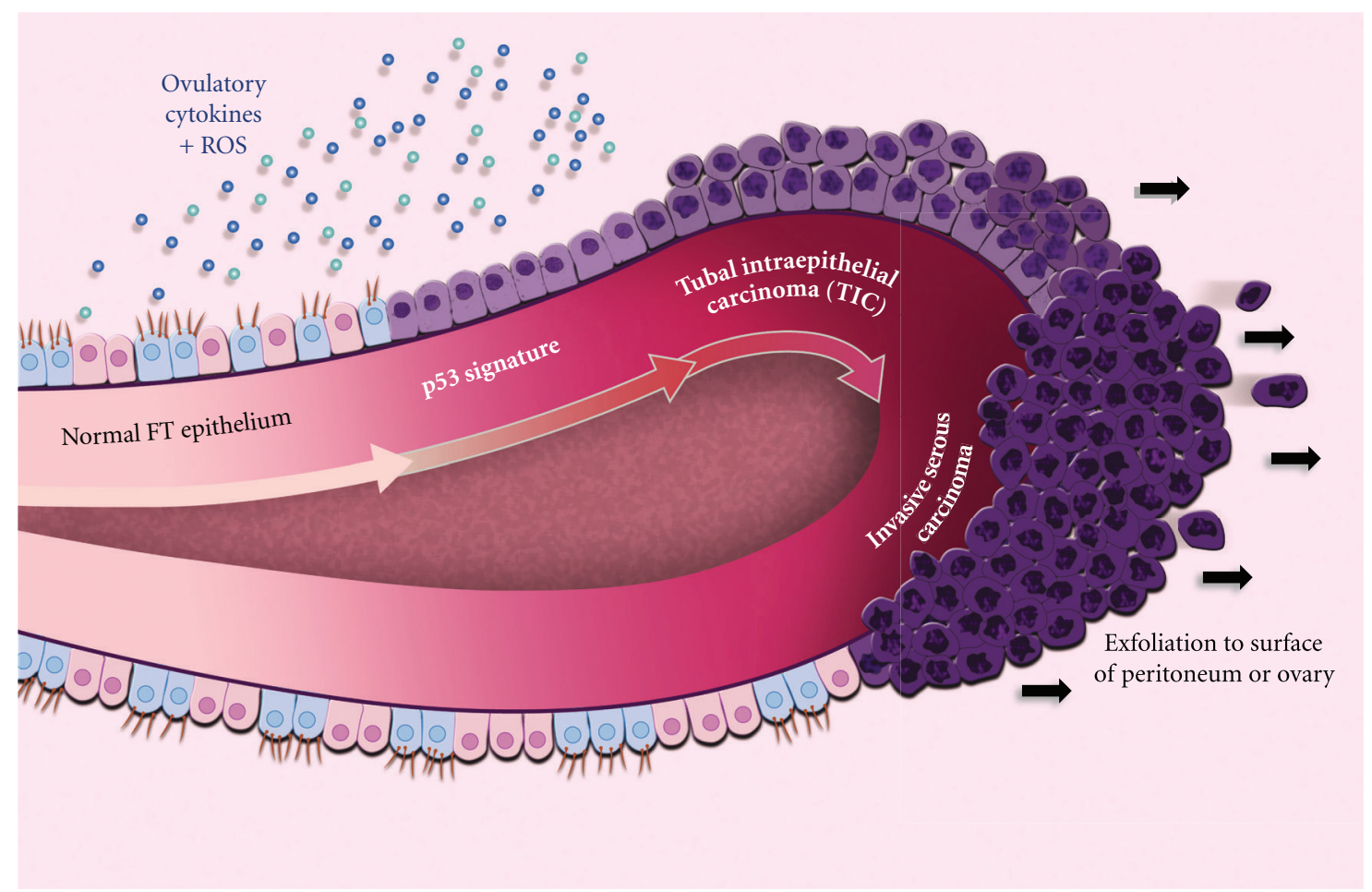

FIGURE 3: Diagram of a fimbrial plica, illustrating the stepwise progression of normal fallopian tube epithelium to invasive serous carcinoma. The fallopian tube epithelium (FTE) is composed of a single layer of ciliated and secretory cells that are exposed to ovulation-associated inflammatory cytokines and reactive oxygen species (ROS). Repetitive genotoxic stress causes DNA damage and induces $p 53$ mutation, leading to the clonal expansion of normal looking FTE cells of secretory phenotype. This stretch of damaged cells—-termed a " $p 53$ signature" — stains strongly for $p 53$ and $\gamma$-H2AX. Further genetic "hits" enable cells to acquire a proliferative capacity, giving rise to tubal intraepithelial carcinoma (TIC). As a TIC progresses to invasive serous carcinoma, malignant cells are exfoliated from the fimbria, whereupon they may spread rapidly to the surface of the peritoneum and/or ovary. Exfoliation may also occur from TICs prior to fimbrial invasion.

by breeding transgenic animals that express TVA under the control of a tissue-specific gene promoter. However, since no MOSE-specific promoters exist, they removed the ovaries from a TVA expressing mouse, infected them in vitro, then implanted them orthotopically into a recipient mouse. Using this method, they were able to demonstrate the importance of TP53 in suppressing ovarian tumorigenesis. Specifically, they showed that introduction of a trio of oncogenes ( $c$ $M Y C, K R A S$, and $A K T$ ) into $p 53^{+/+}$MOSE could not induce tumor formation, while introducing any two of the same oncogenes induced rapid tumor formation in $p 53^{-/-}$mice. All three of these models gave rise to poorly differentiated tumors resembling serous ovarian carcinomas and exhibited intraperitoneal dissemination.

There have also been attempts to create subtypespecific mouse models. Dinulescu et al. successfully generated tumors with endometrioid histology by using the CreLox system to conditionally activate oncogenic KRAS and inactivate PTEN [117]. Using this system, they demonstrated that expression of activated KRAS or deletion of PTEN in MOSE led to an endometriosis-like condition, characterized by the presence of benign glandular lesions in the ovary. In contrast, the combination of both genetic mutations induced formation of invasive and metastatic adenocarcinomas resembling human ovarian endometrioid tumors. Their model nicely recapitulates the stepwise progression of
Type I ovarian tumors. However, KRAS mutations are not commonly found in the endometrioid subtype. A second endometrioid tumor model developed by Wu et al. used the Cre-Lox system to delete PTEN and APC tumor suppressor genes, again giving rise to tumors with endometrioid histologies [118]. Although APC mutations are not characteristic of endometrioid ovarian carcinomas, they serve to deregulate the same pathway as $\beta$-catenin mutations-specifically, the WNT signaling pathway.

Mouse models that can faithfully reproduce both the genotypic and phenotypic characteristics of ovarian tumors are crucial for the development of targeted therapies. Current ovarian carcinoma models indicate that there are two divergent pathways to ovarian tumorigenesis, each giving rise to tumors with very different characteristics (Types I and II). In attempting to model these tumor types, it is important to consider that many Type II tumors may arise from extraovarian sites-most notably, the fallopian tube epithelium. This is of critical importance, for example, in the context of orthotopic tumor cell implantation.

Recent revelations regarding the tubal origin of highgrade serous ovarian carcinomas present a challenge because, while human OSE cells have been routinely cultured for many years, FTE cells are a relatively scare commodity. There are no readily available human FTE cell lines and primary human FTE can be difficult to obtain. Nevertheless, models 
of FTE must be created in order to study the mechanisms of tubal/ovarian serous carcinoma development. Only a handful of labs thus far have attempted to culture or propagate FTE cells in vitro, the majority of them working within the field of reproductive biology [119-124]. As mentioned earlier, the FTE is a complex columnar epithelium composed of both secretory and ciliated cell types. However, ciliated FTE cells tend to either die or rapidly dedifferentiate when grown in vitro, resulting in a complete loss of the ciliated cell phenotype from FTE cocultures. Serous tubal/ovarian carcinomas are exclusively secretory in nature, suggesting that ciliated cells must be either less susceptible to malignant transformation or more apt to undergo cell death in response to genotoxic stressors in their microenvironment. To address such issues, a model system is required in which both ciliated and secretory cells remain viable, so that the behaviors of each cell type may be readily compared and contrasted.

To preserve the phenotypic integrity of FTE cocultures, they may be grown on collagen-coated porous filters, as described by Rajagopal et al. for the culture of monkey oviductal cells [125]. Similar techniques have been used to construct polarized cultures of respiratory epithelial cells [126]. Our lab has recently established an analogous "ex vivo" model of human FTE (unpublished data). Using this FTE coculture system we aim to answer several important questions, including the following: What are the molecular mechanisms driving FTE malignant transformation? Can transformed FTE cells progress to serous tubal intraepithelial carcinoma? Which molecules may be targeted in a therapeutic context to halt serous carcinoma progression? Are there FTE-specific genes that can be exploited for the development of a tubal serous carcinoma mouse model? Can we identify novel biomarkers relevant to serous tumor progression? Our studies must ultimately also consider the role of the tumor microenvironment, since it is apparent that multicellular interactions contribute to serous tumor metastasis and are important factors in a therapeutic context $[127,128]$. Overall, these research efforts will offer new insights into the nature of the FTE and its propensity for malignant transformation, and thus, advance our understanding of ovarian cancer pathogenesis.

\section{Acknowledgments}

The authors wish to thank Drs. Kevin Elias and Michelle Hirsch for their insightful comments and thoughtful suggestions in reviewing this manuscript. Their research is supported by grants from the NIH-National Cancer Institute (K08 CA108748, R21 CA12468, P50 CA105009), the Ovarian Cancer Research Fund, the Fannie E. Ripple Foundation, the Robert and Deborah First Ovarian Cancer Research Fund, and the Randi and Joel Cutler Ovarian Cancer Research Fund.

\section{References}

[1] A. Jemal, R. Siegel, E. Ward, et al., "Cancer statistics, 2008," CA: A Cancer Journal for Clinicians, vol. 58, no. 2, pp. 71-96, 2008.
[2] P. Boyle and B. Levin, International Agency for Research on Cancer, and World Health Organization, "World cancer report 2008”, Distributed by WHO Press, Geneva, Switzerland, 2008.

[3] J. L. Benedet, H. Bender, H. Jones III, H. Y. Ngan, and S. Pecorelli, "FIGO staging classifications and clinical practice guidelines in the management of gynecologic cancers. FIGO Committee on Gynecologic Oncology," International Journal of Gynecology \& Obstetrics, vol. 70, no. 2, pp. 209-262, 2000.

[4] L. H. Smith, C. R. Morris, S. Yasmeen, A. Parikh-Patel, R. D. Cress, and P. S. Romano, "Ovarian cancer: can we make the clinical diagnosis earlier?" Cancer, vol. 104, no. 7, pp. 13981407, 2005.

[5] B. A. Goff, L. Mandel, H. G. Muntz, and C. H. Melancon, "Ovarian carcinoma diagnosis: results of a national ovarian cancer survey," Cancer, vol. 89, no. 10, pp. 2068-2075, 2000.

[6] C. R. Bankhead, C. Collins, H. Stokes-Lampard, et al., "Identifying symptoms of ovarian cancer: a qualitative and quantitative study," BJOG, vol. 115 , no. 8, pp. 1008-1014, 2008.

[7] R. Twombly, "Cancer killer may be "silent" no more," Journal of the National Cancer Institute, vol. 99, no. 18, pp. 13591361, 2007.

[8] T. H. Bourne, S. Campbell, K. M. Reynolds, et al., "Screening for early familial ovarian cancer with transvaginal ultrasonography and colour blood flow imaging," British Medical Journal, vol. 306, no. 6884, pp. 1025-1029, 1993.

[9] J. R. van Nagell Jr., P. D. DePriest, M. B. Reedy, et al., "The efficacy of transvaginal sonographic screening in asymptomatic women at risk for ovarian cancer," Gynecologic Oncology, vol. 77, no. 3, pp. 350-356, 2000.

[10] S. Sato, Y. Yokoyama, T. Sakamoto, M. Futagami, and Y. Saito, "Usefulness of mass screening for ovarian carcinoma using transvaginal ultrasonography," Cancer, vol. 89, no. 3, pp. 582-588, 2000.

[11] J. P. Lerner, I. E. Timor-Tritsch, A. Federman, and G. Abramovich, "Transvaginal ultrasonographic characterization of ovarian masses with an improved, weighted scoring system," American Journal of Obstetrics \& Gynecology, vol. 170, no. 1, pp. 81-85, 1994.

[12] D. A. Fishman, L. Cohen, S. V. Blank, et al., "The role of ultrasound evaluation in the detection of early-stage epithelial ovarian cancer," American Journal of Obstetrics \& Gynecology, vol. 192, no. 4, pp. 1214-1222, 2005.

[13] J. R. van Nagell Jr., P. D. DePriest, F. R. Ueland, et al., “Ovarian cancer screening with annual transvaginal sonography: findings of 25,000 women screened," Cancer, vol. 109, no. 9, pp. 1887-1896, 2007.

[14] R. J. Kurman, K. Visvanathan, R. Roden, T. C. Wu, and I.M. Shih, "Early detection and treatment of ovarian cancer: shifting from early stage to minimal volume of disease based on a new model of carcinogenesis," American Journal of Obstetrics \& Gynecology, vol. 198, no. 4, pp. 351-356, 2008.

[15] L. Valentin, L. Skoog, and E. Epstein, "Frequency and type of adnexal lesions in autopsy material from postmenopausal women: ultrasound study with histological correlation," Ultrasound in Obstetrics and Gynecology, vol. 22, no. 3, pp. 284-289, 2003.

[16] E. F. C. Murta and R. S. Nomelini, "Early diagnosis and predictors of malignancy of adnexal masses," Current Opinion in Obstetrics and Gynecology, vol. 18, no. 1, pp. 14-19, 2006.

[17] U. Menon, A. Gentry-Maharaj, R. Hallett, et al., "Sensitivity and specificity of multimodal and ultrasound screening for ovarian cancer, and stage distribution of detected cancers: 
results of the prevalence screen of the UK Collaborative Trial of Ovarian Cancer Screening (UKCTOCS)," The Lancet Oncology, vol. 10, no. 4, pp. 327-340, 2009.

[18] I. J. Jacobs, S. J. Skates, N. MacDonald, et al., "Screening for ovarian cancer: a pilot randomised controlled trial," The Lancet, vol. 353, no. 9160, pp. 1207-1210, 1999.

[19] I. Jacobs and R. C. Bast Jr., "The CA 125 tumour-associated antigen: a review of the literature," Human Reproduction, vol. 4, no. 1, pp. 1-12, 1989.

[20] S. E. Kabawat, R. C. Bast Jr., A. K. Bhan, W. R. Welch, R. C. Knapp, and R. B. Colvin, "Tissue distribution of a coelomicepithelium-related antigen recognized by the monoclonal antibody OC125," International Journal of Gynecological Pathology, vol. 2, no. 3, pp. 275-285, 1983.

[21] R. C. Bast Jr., T. L. Klug, E. St. John, et al., "A radioimmunoassay using a monoclonal antibody to monitor the course of epithelial ovarian cancer," The New England Journal of Medicine, vol. 309, no. 15, pp. 883-887, 1983.

[22] P. Kenemans, G. J. van Kamp, P. Oehr, and R. A. Verstraeten, "Heterologous double determinant immunoradiometric assay CA 125 II: reliable second-generation immunoassay for determining CA 125 in serum," Clinical Chemistry, vol. 39, no. 12, pp. 2509-2513, 1993.

[23] K. Nustad, R. C. Bast Jr., T. J. O’Brien, et al., “Specificity and affinity of 26 monoclonal antibodies against the CA 125 antigen: first report from the ISOBM TD-1 workshop," Tumor Biology, vol. 17, no. 4, pp. 196-219, 1996.

[24] R. C. Bast Jr., N. Urban, V. Shridhar, et al., "Early detection of ovarian cancer: promise and reality," Cancer Treatment and Research, vol. 107, pp. 61-97, 2002.

[25] E. V. S. Høgdall, L. Christensen, S. K. Kjaer, et al., "CA125 expression pattern, prognosis and correlation with serum CA125 in ovarian tumor patients. From The Danish "MALOVA" Ovarian Cancer Study," Gynecologic Oncology, vol. 104, no. 3, pp. 508-515, 2007.

[26] E. P. Beck, A. Moldenhauer, E. Merkle, et al., "CA 125 production and release by ovarian cancer cells in vitro," International Journal of Biological Markers, vol. 13, no. 4, pp. 200-206, 1998.

[27] C. Marth, A. G. Zeimet, G. Bock, and G. Daxenbichler, "Modulation of tumour marker CA-125 expression in cultured ovarian carcinoma cells," European Journal of Cancer Part A, vol. 28, no. 12, pp. 2002-2006, 1992.

[28] R. C. Bast Jr., M. Feeney, H. Lazarus, L. M. Nadler, R. B. Colvin, and R. C. Knapp, "Reactivity of a monoclonal antibody with human ovarian carcinoma," Journal of Clinical Investigation, vol. 68, no. 5, pp. 1331-1337, 1981.

[29] V. R. Zurawski Jr., H. Orjaseter, A. Andersen, and E. Jellum, "Elevated serum CA 125 levels prior to diagnosis of ovarian neoplasia: relevance for early detection of ovarian cancer," International Journal of Cancer, vol. 42, no. 5, pp. 677-680, 1988.

[30] H. Meden and A. Fattani-Meiodi, "CA 125 in benign gynecological conditions," International Journal of Biological Markers, vol. 13, no. 4, pp. 231-237, 1998.

[31] K. J. Helzlsouer, T. L. Bush, A. J. Alberg, K. M. Bass, H. Zacur, and G. W. Comstock, "Prospective study of serum CA-125 levels as markers of ovarian cancer," Journal of the American Medical Association, vol. 269, no. 9, pp. 1123-1126, 1993.

[32] R. E. Hawkins, K. Roberts, E. Wiltshaw, J. Mundy, I. J. Fryatt, and V. R. McCready, "The prognostic significance of the halflife of serum CA 125 in patients responding to chemotherapy for epithelial ovarian carcinoma," British Journal of Obstetrics and Gynaecology, vol. 96, no. 12, pp. 1395-1399, 1989.
[33] A. Gadducci, P. Zola, F. Landoni, et al., "Serum half-life of CA 125 during early chemotherapy as an independent prognostic variable for patients with advanced epithelial ovarian cancer: results of a Multicentric Italian Study," Gynecologic Oncology, vol. 58, no. 1, pp. 42-47, 1995.

[34] S. J. Skates, U. Menon, N. MacDonald, et al., "Calculation of the risk of ovarian cancer from serial CA-125 values for preclinical detection in postmenopausal women," Journal of Clinical Oncology, vol. 21, supplement 10, pp. 206s-210s, 2003.

[35] S. J. Skates, F.-J. Xu, Y.-H. Yu, et al., "Toward an optimal algorithm for ovarian cancer screening with longitudinal tumor markers," Cancer, vol. 76, supplement 10, pp. 20042010, 1995.

[36] S. J. Skates, D. K. Pauler, and I. J. Jacobs, "Screening based on the risk of cancer calculation from Bayesian hierarchical changepoint and mixture models of longitudinal markers," Journal of the American Statistical Association, vol. 96, pp. 429-439, 2001.

[37] R. Drapkin, H. H. von Horsten, Y. Lin, et al., "Human epididymis protein 4 (HE4) is a secreted glycoprotein that is overexpressed by serous and endometrioid ovarian carcinomas," Cancer Research, vol. 65, no. 6, pp. 2162-2169, 2005.

[38] R. G. Moore, A. K. Brown, M. C. Miller, et al., "The use of multiple novel tumor biomarkers for the detection of ovarian carcinoma in patients with a pelvic mass," Gynecologic Oncology, vol. 108, no. 2, pp. 402-408, 2008.

[39] I. Hellström, J. Raycraft, M. Hayden-Ledbetter, et al., "The HE4 (WFDC2) protein is a biomarker for ovarian carcinoma," Cancer Research, vol. 63, no. 13, pp. 3695-3700, 2003.

[40] K. Huhtinen, P. Suvitie, J. Hiissa, et al., "Serum HE4 concentration differentiates malignant ovarian tumours from ovarian endometriotic cysts," British Journal of Cancer, vol. 100, no. 8, pp. 1315-1319, 2009.

[41] R. G. Moore, D. S. McMeekin, A. K. Brown, et al., "A novel multiple marker bioassay utilizing HE4 and CA125 for the prediction of ovarian cancer in patients with a pelvic mass," Gynecologic Oncology, vol. 112, no. 1, pp. 40-46, 2009.

[42] Z. Zhang, Y. Yu, F. Xu, et al., "Combining multiple serum tumor markers improves detection of stage I epithelial ovarian cancer," Gynecologic Oncology, vol. 107, no. 3, pp. 526-531, 2007.

[43] I. Visintin, Z. Feng, G. Longton, et al., "Diagnostic markers for early detection of ovarian cancer," Clinical Cancer Research, vol. 14, no. 4, pp. 1065-1072, 2008.

[44] V. Nosov, F. Su, M. Amneus, et al., "Validation of serum biomarkers for detection of early-stage ovarian cancer," American Journal of Obstetrics \& Gynecology, vol. 200, no. 6, pp. 639.e1-639.e5, 2009.

[45] V. W. Chen, B. Ruiz, J. L. Killeen, et al., "Pathology and classification of ovarian tumors," Cancer, vol. 97, supplement 10, pp. 2631-2642, 2003.

[46] F. A. Tavassoli and P. Devilee, Pathology and Genetics of Tumours of the Breast and Female Genital Organs, International Agency for Research on Cancer, and World Health Organization, IAPS Press, Lyon, France, 2003.

[47] L. Dubeau, "The cell of origin of ovarian epithelial tumors and the ovarian surface epithelium dogma: does the emperor have no clothes?" Gynecologic Oncology, vol. 72, no. 3, pp. 437-442, 1999.

[48] N. Auersperg, T. Ota, and G. W. E. Mitchell, "Early events in ovarian epithelial carcinogenesis: progress and problems 
in experimental approaches," International Journal of Gynecological Cancer, vol. 12, no. 6, pp. 691-703, 2002.

[49] J. D. Seidman, I. Horkayne-Szakaly, M. Haiba, C. R. Boice, R. J. Kurman, and B. M. Ronnett, "The histologic type and stage distribution of ovarian carcinomas of surface epithelial origin," International Journal of Gynecological Pathology, vol. 23, no. 1, pp. 41-44, 2004.

[50] C. N. Landen Jr., M. J. Birrer, and A. K. Sood, "Early events in the pathogenesis of epithelial ovarian cancer," Journal of Clinical Oncology, vol. 26, no. 6, pp. 995-1005, 2008.

[51] I.-M. Shih and R. J. Kurman, "Ovarian tumorigenesis: a proposed model based on morphological and molecular genetic analysis," American Journal of Pathology, vol. 164, no. 5, pp. 1511-1518, 2004.

[52] D. S. McMeekin, R. A. Burger, A. Manetta, P. DiSaia, and M. L. Berman, "Endometrioid adenocarcinoma of the ovary and its relationship to endometriosis," Gynecologic Oncology, vol. 59, no. 1, pp. 81-86, 1995.

[53] H. Yoshikawa, H. Jimbo, S. Okada, et al., "Prevalence of endometriosis in ovarian cancer," Gynecologic and Obstetric Investigation, vol. 50, supplement 1, pp. 11-17, 2000.

[54] M. Erzen, S. Rakar, B. Klancnik, and K. Syrjanen, "Endometriosis-associated ovarian carcinoma (EAOC): an entity distinct from other ovarian carcinomas as suggested by a nested case-control study," Gynecologic Oncology, vol. 83, no. 1, pp. 100-108, 2001.

[55] S. C. Modesitt, G. Tortolero-Luna, J. B. Robinson, D. M. Gershenson, and J. K. Wolf, "Ovarian and extraovarian endometriosis-associated cancer," Obstetrics and Gynecology, vol. 100, no. 4, pp. 788-795, 2002.

[56] R. C. Stern, R. Dash, R. C. Bentley, M. J. Snyder, A. F. Haney, and S. J. Robboy, "Malignancy in endometriosis: frequency and comparison of ovarian and extraovarian types," International Journal of Gynecological Pathology, vol. 20, no. 2, pp. 133-139, 2001.

[57] R. Sainz de la Cuesta, J. H. Eichhorn, L. W. Rice, A. F. Fuller Jr., N. Nikrui, and B. A. Goff, "Histologic transformation of benign endometriosis to early epithelial ovarian cancer," Gynecologic Oncology, vol. 60, no. 2, pp. 238-244, 1996.

[58] E. J. Thomas and I. G. Campbell, "Molecular genetic defects in endometriosis," Gynecologic and Obstetric Investigation, vol. 50, supplement 1, pp. 44-50, 2000.

[59] H. Itamochi, J. Kigawa, T. Sugiyama, Y. Kikuchi, M. Suzuki, and N. Terakawa, "Low proliferation activity may be associated with chemoresistance in clear cell carcinoma of the ovary," Obstetrics and Gynecology, vol. 100, no. 2, pp. 281$287,2002$.

[60] T. Sugiyama, T. Kamura, J. Kigawa, et al., "Clinical characteristics of clear cell carcinoma of the ovary: a distinct histologic type with poor prognosis and resistance to platinum-based chemotherapy," Cancer, vol. 88, no. 11, pp. 2584-2589, 2000.

[61] D. R. Schwartz, S. L. R. Kardia, K. A. Shedden, et al., "Gene expression in ovarian cancer reflects both morphology and biological behavior, distinguishing clear cell from other poorprognosis ovarian carcinomas," Cancer Research, vol. 62, no. 16, pp. 4722-4729, 2002.

[62] S. Marchini, P. Mariani, G. Chiorino, et al., "Analysis of gene expression in early-stage ovarian cancer," Clinical Cancer Research, vol. 14, no. 23, pp. 7850-7860, 2008.

[63] M. V. Iorio, R. Visone, G. Di Leva, et al., "MicroRNA signatures in human ovarian cancer," Cancer Research, vol. 67, no. 18, pp. 8699-8707, 2007.

[64] K. K. Zorn, T. Bonome, L. Gangi, et al., "Gene expression profiles of serous, endometrioid, and clear cell subtypes of ovarian and endometrial cancer," Clinical Cancer Research, vol. 11, no. 18, pp. 6422-6430, 2005.

[65] T. Bonome, J.-Y. Lee, D.-C. Park, et al., "Expression profiling of serous low malignant potential, low-grade, and high-grade tumors of the ovary," Cancer Research, vol. 65, no. 22, pp. 10602-10612, 2005.

[66] M. Kobel, S. E. Kalloger, N. Boyd, et al., "Ovarian carcinoma subtypes are different diseases: implications for biomarker studies," PLoS Medicine, vol. 5, no. 12, article e232, 2008.

[67] G. Singer, R. Stöhr, L. Cope, et al., "Patterns of p53 mutations separate ovarian serous borderline tumors and low- and high-grade carcinomas and provide support for a new model of ovarian carcinogenesis: a mutational analysis with immunohistochemical correlation," The American Journal of Surgical Pathology, vol. 29, no. 2, pp. 218-224, 2005.

[68] S. A. Cannistra, "Cancer of the ovary," The New England Journal of Medicine, vol. 351, no. 24, pp. 2519-2529, 2004.

[69] S. A. South, H. Vance, C. Farrell, et al., "Consideration of hereditary nonpolyposis colorectal cancer in BRCA mutation-negative familial ovarian cancers," Cancer, vol. 115, no. 2, pp. 324-333, 2009.

[70] R. Scully and D. M. Livingston, "In search of the tumoursuppressor functions of BRCA1 and BRCA2," Nature, vol. 408, no. 6811, pp. 429-432, 2000.

[71] M. Tsai-Turton, A. Santillan, D. Lu, et al., "p53 autoantibodies, cytokine levels and ovarian carcinogenesis," Gynecologic Oncology, vol. 114, no. 1, pp. 12-17, 2009.

[72] T. J. Herzog and B. Pothuri, "Ovarian cancer: a focus on management of recurrent disease," Nature Clinical Practice Oncology, vol. 3, no. 11, pp. 604-611, 2006.

[73] N. Auersperg, S. L. Maines-Bandiera, H. G. Dyck, and P. A. Kruk, "Characterization of cultured human ovarian surface epithelial cells: phenotypic plasticity and premalignant changes," Laboratory Investigation, vol. 71, no. 4, pp. 510-518, 1994.

[74] B. Czernobilsky, R. Moll, R. Levy, and W. W. Franke, "Co-expression of cytokeratin and vimentin filaments in mesothelial, granulosa and rete ovarii cells of the human ovary," European Journal of Cell Biology, vol. 37, pp. 175-190, 1985.

[75] C. H. Siemens and N. Auersperg, "Serial propagation of human ovarian surface epithelium in tissue culture," Journal of Cellular Physiology, vol. 134, no. 3, pp. 347-356, 1988.

[76] P. A. Kruk, V.-J. Uitto, J. D. Firth, S. Dedhar, and N. Auersperg, "Reciprocal interactions between human ovarian surface epithelial cells and adjacent extracellular matrix," Experimental Cell Research, vol. 215, no. 1, pp. 97-108, 1994.

[77] W. J. Murdoch and J. F. Martinchick, "Oxidative damage to DNA of ovarian surface epithelial cells affected by ovulation: carcinogenic implication and chemoprevention," Experimental Biology and Medicine, vol. 229, no. 6, pp. 546552, 2004.

[78] R. Drapkin and J. L. Hecht, "Pathogenesis of ovarian cancer," in Diagnostic gynecologic and obstetric pathology, Elsevier Saunders, Philadelphia, Pa, USA, 2006.

[79] R. Drapkin, C. P. Crum, and J. L. Hecht, "Expression of candidate tumor markers in ovarian carcinoma and benign ovary: evidence for a link between epithelial phenotype and neoplasia," Human Pathology, vol. 35, no. 8, pp. 1014-1021, 2004.

[80] L. Dubeau, "The cell of origin of ovarian epithelial tumours," The Lancet Oncology, vol. 9, no. 12, pp. 1191-1197, 2008. 
[81] A. S. T. Wong and P. C. K. Leung, "Role of endocrine and growth factors on the ovarian surface epithelium," Journal of Obstetrics and Gynaecology Research, vol. 33, no. 1, pp. 3-16, 2007.

[82] J. Permuth-Wey and T. A. Sellers, "Epidemiology of ovarian cancer," Methods in Molecular Biology, vol. 472, pp. 413-437, 2009.

[83] B. H. Ortiz, M. Ailawadi, C. Colitti, et al., "Second primary or recurrence? Comparative patterns of p53 and K-ras mutations suggest that serous borderline ovarian tumors and subsequent serous carcinomas are unrelated tumors," Cancer Research, vol. 61, no. 19, pp. 7264-7267, 2001.

[84] R. F. Caduff, S. M. Svoboda-Newman, A. W. Ferguson, C. M. Johnston, and T. S. Frank, "Comparison of mutations of KiRAS and p53 immunoreactivity in borderline and malignant epithelial ovarian tumors," The American Journal of Surgical Pathology, vol. 23, no. 3, pp. 323-328, 1999.

[85] G. Singer, R. J. Kurman, H.-W. Chang, S. K. R. Cho, and I.M. Shih, "Diverse tumorigenic pathways in ovarian serous carcinoma," American Journal of Pathology, vol. 160, no. 4, pp. 1223-1228, 2002.

[86] J. D. Seidman and R. J. Kurman, "Subclassification of serous borderline tumors of the ovary into benign and malignant types: a clinicopathologic study of 65 advanced stage cases," The American Journal of Surgical Pathology, vol. 20, no. 11, pp. 1331-1345, 1996.

[87] A. E. S. Sehdev, P. S. Sehdev, and R. J. Kurman, "Noninvasive and invasive micropapillary (low-grade) serous carcinoma of the ovary: a clinicopathologic analysis of 135 cases," The American Journal of Surgical Pathology, vol. 27, no. 6, pp. 725736, 2003.

[88] C. Peyssonnaux and A. Eychene, "The Raf/MEK/ERK pathway: new concepts of activation," Biology of the Cell, vol. 93, no. 1-2, pp. 53-62, 2001.

[89] G. Singer, R. Oldt III, Y. Cohen, et al., "Mutations in BRAF and KRAS characterize the development of low-grade ovarian serous carcinoma," Journal of the National Cancer Institute, vol. 95, no. 6, pp. 484-486, 2003.

[90] K. Obata, S. J. Morland, R. H. Watson, et al., "Frequent PTEN/MMAC mutations in endometrioid but not serous or mucinous epithelial ovarian tumors," Cancer Research, vol. 58, no. 10, pp. 2095-2097, 1998.

[91] D. Shahbazian, P. P. Roux, V. Mieulet, et al., "The mTOR/PI3K and MAPK pathways converge on eIF4B to control its phosphorylation and activity," The EMBO Journal, vol. 25, no. 12, pp. 2781-2791, 2006.

[92] E. Janda, K. Lehmann, I. Killisch, et al., "Ras and TGF $\beta$ cooperatively regulate epithelial cell plasticity and metastasis: dissection of Ras signaling pathways," Journal of Cell Biology, vol. 156, no. 2, pp. 299-313, 2002.

[93] M. Sabbah, S. Emami, G. Redeuilh, et al., "Molecular signature and therapeutic perspective of the epithelial-tomesenchymal transitions in epithelial cancers," Drug Resistance Updates, vol. 11, no. 4-5, pp. 123-151, 2008.

[94] W.-Y. Chan, K.-K. Cheung, J. O. Schorge, et al., "Bcl-2 and p53 protein expression, apoptosis, and p53 mutation in human epithelial ovarian cancers," American Journal of Pathology, vol. 156, no. 2, pp. 409-417, 2000.

[95] M. F. Kohler, J. R. Marks, R. W. Wiseman, et al., "Spectrum of mutation and frequency of allelic deletion of the p53 gene in ovarian cancer," Journal of the National Cancer Institute, vol. 85, no. 18 , pp. 1513-1519, 1993.
[96] J. Kupryjanczyk, A. D. Thor, R. Beauchamp, et al., "p53 gene mutations and protein accumulation in human ovarian cancer," Proceedings of the National Academy of Sciences of the United States of America, vol. 90, no. 11, pp. 4961-4965, 1993.

[97] W.-H. Wen, A. Reles, I. B. Runnebaum, et al., "p53 mutations and expression in ovarian cancers: correlation with overall survival," International Journal of Gynecological Pathology, vol. 18, no. 1, pp. 29-41, 1999.

[98] J. S. Ross, F. Yang, B. V. S. Kallakury, C. E. Sheehan, R. A. Ambros, and P. J. Muraca, "HER-2/neu oncogene amplification by fluorescence in situ hybridization in epithelial tumors of the ovary," American Journal of Clinical Pathology, vol. 111, no. 3, pp. 311-316, 1999.

[99] J. Q. Cheng, A. K. Godwin, A. Bellacosa, et al., "AKT2, a putative oncogene encoding a member of a subfamily of protein-serine/threonine kinases, is amplified in human ovarian carcinomas," Proceedings of the National Academy of Sciences of the United States of America, vol. 89, no. 19, pp. 9267-9271, 1992.

[100] H. A. Risch, J. R. McLaughlin, D. E. C. Cole, et al., "Population BRCA1 and BRCA2 mutation frequencies and cancer penetrances: a kin-cohort study in Ontario, Canada," Journal of the National Cancer Institute, vol. 98, no. 23, pp. 1694-1706, 2006.

[101] R. Wooster and B. L. Weber, "Breast and ovarian cancer," The New England Journal of Medicine, vol. 348, no. 23, pp. 23392347, 2003.

[102] J. M. J. Piek, P. J. van Diest, R. P. Zweemer, et al., “Dysplastic changes in prophylactically removed Fallopian tubes of women predisposed to developing ovarian cancer," Journal of Pathology, vol. 195, no. 4, pp. 451-456, 2001.

[103] M. L. Carcangiu, P. Radice, S. Manoukian, et al., "Atypical epithelial proliferation in fallopian tubes in prophylactic salpingo-oophorectomy specimens from BRCA1 and BRCA2 germline mutation carrier," International Journal of Gynecological Pathology, vol. 23, no. 1, pp. 35-40, 2004.

[104] A. Finch, P. Shaw, B. Rosen, J. Murphy, S. A. Narod, and T. J. Colgan, "Clinical and pathologic findings of prophylactic salpingo-oophorectomies in 159 BRCA1 and BRCA2 carriers," Gynecologic Oncology, vol. 100, no. 1, pp. 58-64, 2006.

[105] K. Leeper, R. Garcia, E. Swisher, B. Goff, B. Greer, and P. Paley, "Pathologic findings in prophylactic oophorectomy specimens in high-risk women," Gynecologic Oncology, vol. 87, no. 1, pp. 52-56, 2002.

[106] F. Medeiros, M. G. Muto, Y. Lee, et al., "The tubal fimbria is a preferred site for early adenocarcinoma in women with familial ovarian cancer syndrome," The American Journal of Surgical Pathology, vol. 30, no. 2, pp. 230-236, 2006.

[107] D. W. Kindelberger, Y. Lee, A. Miron, et al., "Intraepithelial carcinoma of the fimbria and pelvic serous carcinoma: evidence for a causal relationship," The American Journal of Surgical Pathology, vol. 31, no. 2, pp. 161-169, 2007.

[108] Y. Lee, A. Miron, R. Drapkin, et al., "A candidate precursor to serous carcinoma that originates in the distal fallopian tube," Journal of Pathology, vol. 211, no. 1, pp. 26-35, 2007.

[109] E. P. Rogakou, C. Boon, C. Redon, and W. M. Bonner, "Megabase chromatin domains involved in DNA doublestrand breaks in vivo," Journal of Cell Biology, vol. 146, no. 5, pp. 905-915, 1999.

[110] A. K. Folkins, E. A. Jarboe, A. Saleemuddin, et al., "A candidate precursor to pelvic serous cancer ( $\mathrm{p} 53$ signature) 
and its prevalence in ovaries and fallopian tubes from women with BRCA mutations," Gynecologic Oncology, vol. 109, no. 2, pp. 168-173, 2008.

[111] K. Levanon, C. Crum, and R. Drapkin, "New insights into the pathogenesis of serous ovarian cancer and its clinical impact," Journal of Clinical Oncology, vol. 26, no. 32, pp. 5284-5293, 2008.

[112] A. Saleemuddin, A. K. Folkins, L. Garrett, et al., "Risk factors for a serous cancer precursor ("p53 signature") in women with inherited BRCA mutations," Gynecologic Oncology, vol. 111, no. 2, pp. 226-232, 2008.

[113] A. K. Folkins, E. A. Jarboe, M. H. Roh, and C. P. Crum, "Precursors to pelvic serous carcinoma and their clinical implications," Gynecologic Oncology, vol. 113, no. 3, pp. 391396, 2009.

[114] D. C. Connolly, R. Bao, A. Y. Nikitin, et al., "Female mice chimeric for expression of the simian virus $40 \mathrm{TAg}$ under control of the MISIIR promoter develop epithelial ovarian cancer," Cancer Research, vol. 63, no. 6, pp. 1389-1397, 2003.

[115] A. Flesken-Nikitin, K.-C. Choi, J. P. Eng, E. N. Shmidt, and A. Y. Nikitin, "Induction of carcinogenesis by concurrent inactivation of p53 and Rb1 in the mouse ovarian surface epithelium," Cancer Research, vol. 63, no. 13, pp. 3459-3463, 2003.

[116] S. Orsulic, Y. Li, R. A. Soslow, L. A. Vitale-Cross, J. S. Gutkind, and H. E. Varmus, "Induction of ovarian cancer by defined multiple genetic changes in a mouse model system," Cancer Cell, vol. 1, no. 1, pp. 53-62, 2002.

[117] D. M. Dinulescu, T. A. Ince, B. J. Quade, S. A. Shafer, D. Crowley, and T. Jacks, "Role of K-ras and Pten in the development of mouse models of endometriosis and endometrioid ovarian cancer," Nature Medicine, vol. 11, no. 1, pp. 63-70, 2005.

[118] R. Wu, N. Hendrix-Lucas, R. Kuick, et al., "Mouse model of human ovarian endometrioid adenocarcinoma based on somatic defects in the $\mathrm{Wnt} / \beta$-catenin and PI3K/Pten signaling pathways," Cancer Cell, vol. 11, no. 4, pp. 321-333, 2007.

[119] T. Umezu, M. Hanazono, S. Aizawa, and Y. Tomooka, "Characterization of newly established clonal oviductal cell lines and differential hormonal regulation of gene expression," In Vitro Cellular and Developmental Biology-Animal, vol. 39, no. 3-4, pp. 146-156, 2003.

[120] Y.-L. Lee, K.-F. Lee, J.-S. Xu, Y.-L. Wang, S.-W. Tsao, and W. S. B. Yeung, "Establishment and characterization of an immortalized human oviductal cell line," Molecular Reproduction and Development, vol. 59, no. 4, pp. 400-409, 2001.

[121] M. T. Comer, H. J. Leese, and J. Southgate, "Induction of a differentiated ciliated cell phenotype in primary cultures of Fallopian tube epithelium," Human Reproduction, vol. 13, no. 11, pp. 3114-3120, 1998.

[122] H. Ando, M. Kobayashi, S. Toda, F. Kikkawa, T. Masahashi, and S. Mizutani, "Establishment of a ciliated epithelial cell line from human Fallopian tube," Human Reproduction, vol. 15, no. 7, pp. 1597-1603, 2000.

[123] T. Henriksen, T. Tanbo, T. Abyholm, B. R. Oppedal, O. P. Claussen, and T. Hovig, "Epithelial cells from human Fallopian tube in culture," Human Reproduction, vol. 5, no. 1, pp. 25-31, 1990.

[124] A. Bongso, S. C. Ng, H. Sathananthan, P. L. Ng, M. Rauff, and S. S. Ratnam, "Establishment of human ampullary cell cultures," Human Reproduction, vol. 4, no. 5, pp. 486-494, 1989.

[125] M. Rajagopal, T. L. Tollner, W. E. Finkbeiner, G. N. Cherr, and J. H. Widdicombe, "Differentiated structure and function of primary cultures of monkey oviductal epithelium," In Vitro Cellular and Developmental Biology-Animal, vol. 42, no. 8-9, pp. 248-254, 2006.

[126] P. D. Vermeer, L. A. Einwalter, T. O. Moninger, et al., "Segregation of receptor and ligand regulates activation of epithelial growth factor receptor," Nature, vol. 422, no. 6929, pp. 322-326, 2003.

[127] L. Zhang, J. R. Conejo-Garcia, D. Katsaros, et al., "Intratumoral T cells, recurrence, and survival in epithelial ovarian cancer," The New England Journal of Medicine, vol. 348, no. 3, pp. 203-213, 2003.

[128] J. A. Joyce and J. W. Pollard, "Microenvironmental regulation of metastasis," Nature Reviews Cancer, vol. 9, no. 4, pp. 239252, 2009. 


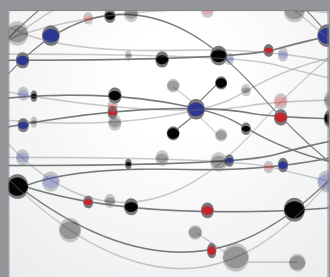

The Scientific World Journal
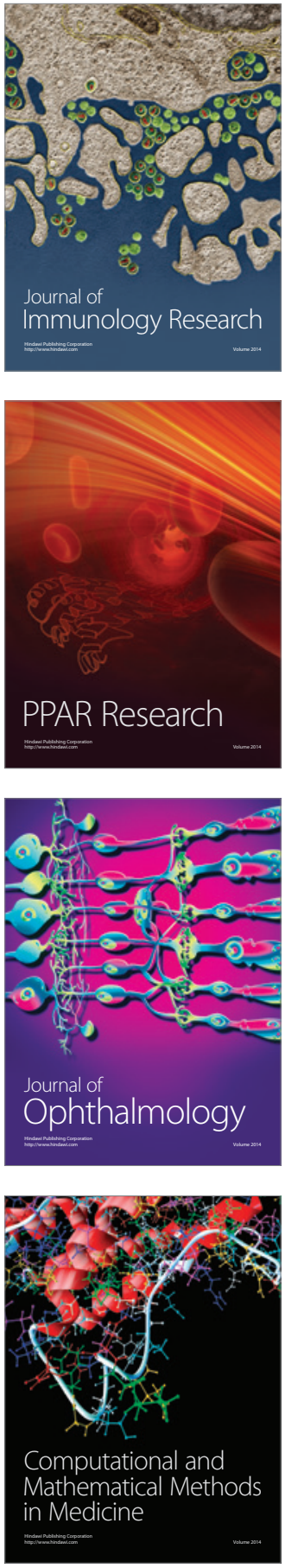

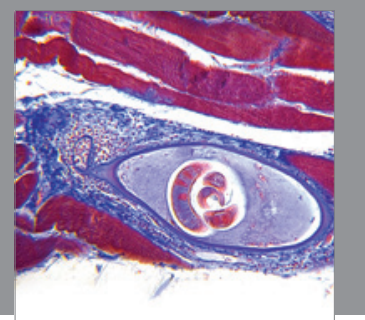

Gastroenterology

Research and Practice
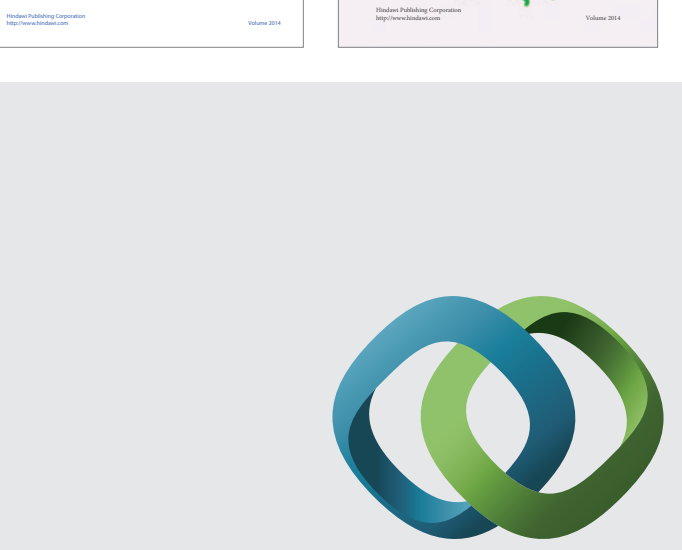

\section{Hindawi}

Submit your manuscripts at

http://www.hindawi.com
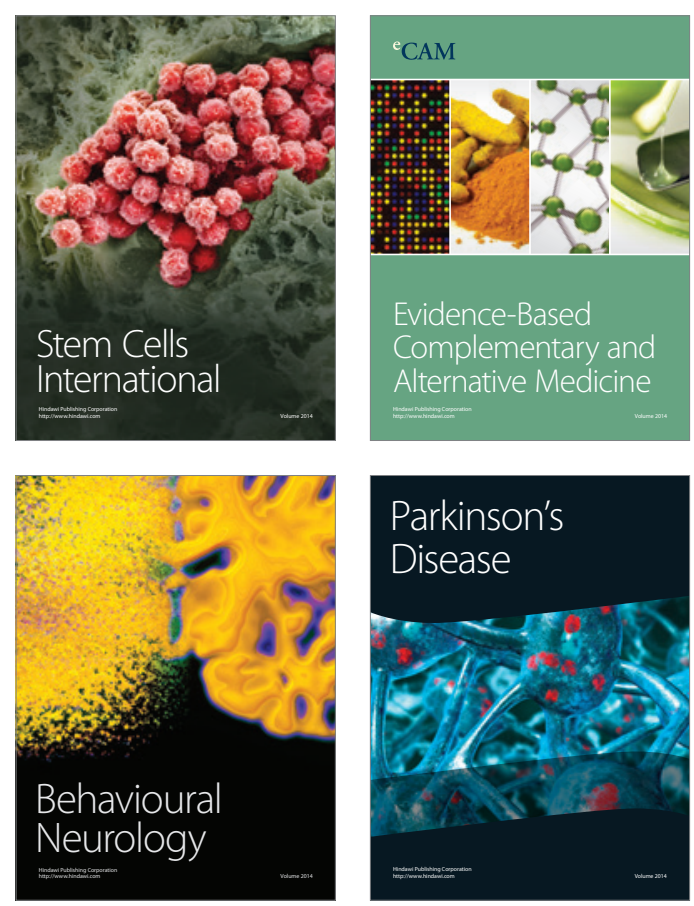

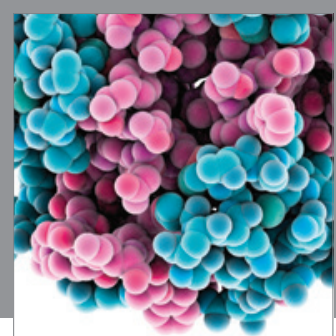

Journal of
Diabetes Research

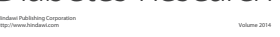

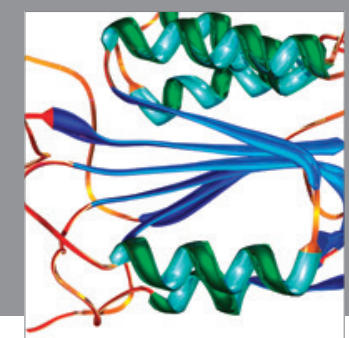

Disease Markers
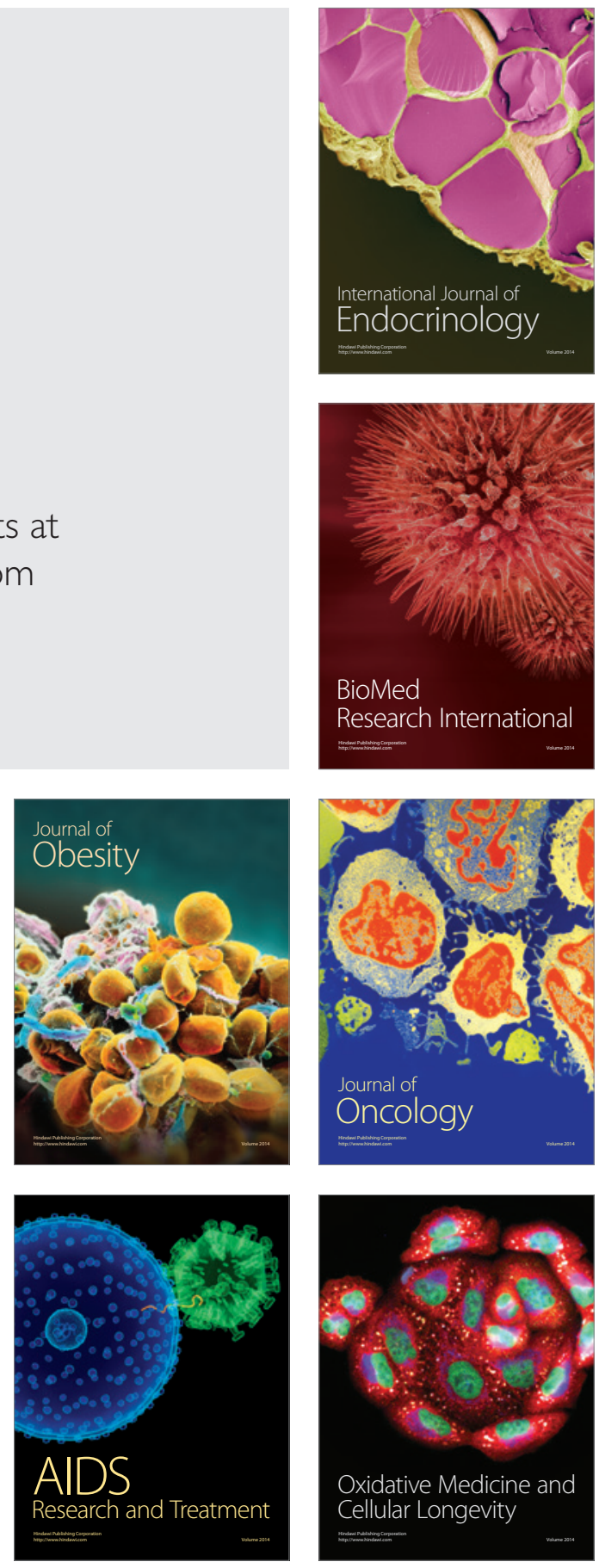